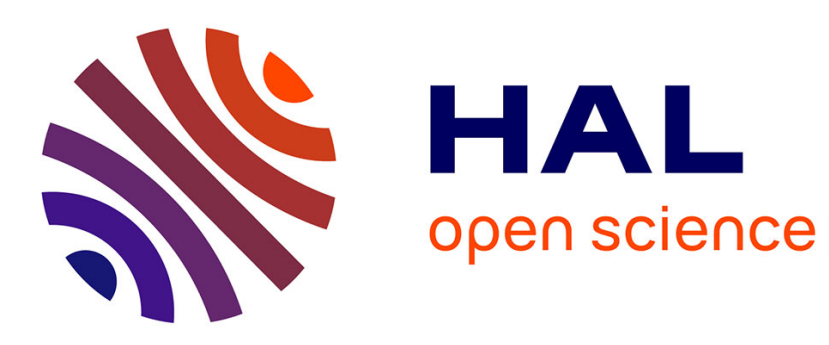

\title{
Effectiveness of corrosion inhibitors in simulated concrete pore solution
}

Ahmed Elshami, Stéphanie Bonnet, Abdelhafid Khelidj, Latefa Sail

\section{To cite this version:}

Ahmed Elshami, Stéphanie Bonnet, Abdelhafid Khelidj, Latefa Sail. Effectiveness of corrosion inhibitors in simulated concrete pore solution. European Journal of Environmental and Civil Engineering, 2018, pp.1 - 21. 10.1080/19648189.2018.1500309 . hal-01923528

\section{HAL Id: hal-01923528 \\ https://hal.science/hal-01923528}

Submitted on 26 Nov 2018

HAL is a multi-disciplinary open access archive for the deposit and dissemination of scientific research documents, whether they are published or not. The documents may come from teaching and research institutions in France or abroad, or from public or private research centers.
L'archive ouverte pluridisciplinaire HAL, est destinée au dépôt et à la diffusion de documents scientifiques de niveau recherche, publiés ou non, émanant des établissements d'enseignement et de recherche français ou étrangers, des laboratoires publics ou privés. 
1 Effectiveness of Corrosion Inhibitors in Simulated Concrete Pore Solution

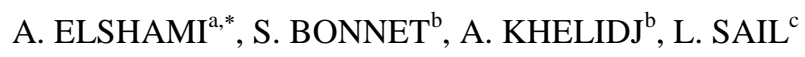

${ }^{a}$ Lecturer at Housing \& Building National Research Centre, 87 El Tahrir St. Dokki-Giza, Egypt Tel (33) 1-40-43-51-65 Fax (33) 1-40-43-54-98

${ }^{b}$ UBL, Université de Nantes, GeM, CNRS UMR 6183, 58 rue Michel Ange (BP420), 44606 Saint Nazaire Cedex, France

${ }^{C}$ EOLE Laboratory, Civil Engineering Department, Faculty of Technology, University Abou Bekr Belkaid, Chetouane BP 230, Tlemcen

\section{ABSTRACT}

Steel embedded in concrete is normally in a passive state against corrosion due to a thin iron oxide layer that forms on the steel surface and remains stable in the high alkaline environment of the concrete. This protective film must be destroyed (depassivation) and this can be mainly done in two ways: by the attack of chlorides on the steel (seawater, de-icing salt, unwashed sea sand, admixtures etc.) or by carbonation. Corrosion inhibitors may be a good alternative to protection steel against corrosion due to its lower cost and easy application. Many researchers are inclined to use surface applied corrosion inhibitors and prefer to use the $\mathrm{Cl}^{-}$/inhibitor parameter as an indication of chloride inhibitor threshold level. The objective of this study was to fill the gap left by public research in developing methods of corrosion control of reinforcement in concrete by synthetic solutions to emulate concrete environment. Three inhibitors were distinguished as passivation inhibitors in real solution extract and synthetic. In this study the tests with calcium nitrite (CNI), sodium monoflurophosphate (MFP) and ethanolamine based inhibitors showed reductions in the overall rates of corrosion after the inhibitive treatments.

Keywords:

Concrete, Corrosion, Chloride, Carbon Steel, CNI, AMA and MFP.

\footnotetext{
${ }^{*}$ Corresponding author. Tel.: +33-1-40-43-51-65; Fax: +33-1-40-43-54-98.

E-mail address: materialhnbrc@yahoo.com (Ahmed. Elshami).
} 


\title{
Effectiveness of Corrosion Inhibitors in Simulated Concrete Pore Solution
}

\author{
A. ELSHAMI ${ }^{\mathrm{a}, *}$, S. BONNET ${ }^{\mathrm{b}}$, A. KHELIDJ ${ }^{\mathrm{b}}$, \\ ${ }^{a}$ Lecturer at Housing \& Building National Research Centre, 87 El Tahrir St. Dokki-Giza, Egypt \\ 58 Bd Lefebvre, F-75732 Paris Cedex 15, France \\ Tel (33) 1-40-43-51-65 Fax (33) 1-40-43-54-98 \\ ${ }^{b}$ GeM (UMR CNRS 6183) Institut de Recherche en Génie Civil et Mécanique IUT de Saint-Nazaire, \\ 58 rue Michel Ange, B.P. 420, F-44606 Saint-Nazaire Cedex- France
}

\section{Introduction}

Minimising the direct and indirect costs of marine structure maintenance and maximising the available capacity is critical to the economic competitiveness of an expanding European Union. The use of corrosion inhibitors - a developing technology - as part of a repair strategy may provide a cost effective solution. A bibliography of over 180 references was assembled. A detailed review was made of material published in the last fifteen years. The review embraced some aspects of CNI, AMA and MFP based inhibitors, used in new construction and repair methods based on cementitious mortars but the main focus was on surface applied corrosion inhibitors. Several studies have been conducted to assess the effects of chloride ions in simulated pore solution. A summary of available literature was given to the most commonly used inhibitors such as CNI, AMA and MFP in artificial concrete pore solutions. In tests with calcium nitrite, sodium monoflurophosphate and ethanolamine based inhibitive treatments Monticelli et al (2000) [1] observed moderate reductions in the overall rates of corrosion after the inhibitive treatments. To ensure this effectiveness the ratio between

\footnotetext{
${ }^{*}$ Corresponding author. Tel.: +33-1-40-43-51-65; Fax: +33-1-40-43-54-98.

E-mail address: materialhnbrc@yahoo.com (Ahmed. Elshami).
} 
inhibitors and chloride ions has to be relatively high (approximately 1) (Elsener et. al. 1999) [2]. Mammoliti et al (1999) [3] have shown that calcium nitrite addition into simulated pore solution at a level of $0.1 \%$ was able to repassivate pre-corroded steel in $1 \%$ chloride. When the chloride was added to the simulated pore solution already containing $0.1 \%$ calcium nitrite, the increase in chloride up to $1.5-2.0 \%$ did not change the potential or the corrosion rate significantly [Ngala, et al, 2002] [4]. However, CNI in solutions of very high $\mathrm{pH}$ value the concentration of $\mathrm{Ca}^{2+}$ ions is strongly limited by the solubility product of $\mathrm{Ca}$ $(\mathrm{OH})_{2}$. The presence of $\mathrm{CNI}$ in the pore solution leads to precipitate calcium hydroxide (and consequent reduction in $\mathrm{pH}$ ) [Li et al, 2000] [5]. Kawamura et al (1997) [6] measured the $\left[\mathrm{Cl}^{-}\right.$ ]$/\left[\mathrm{NO}_{2}^{-}\right]$ratio both in pore solution and in mortar specimens. The free chloride concentration in the pore solution decreased and the $\mathrm{OH}^{-}$content increased with the time of aging. The $\left[\mathrm{Cl}^{-}\right] /\left[\mathrm{NO}_{2}{ }^{-}\right]$ratio remained fairly constant and achieved a value of about 0.8 for $0.5 \%$ of admixed $\mathrm{NaCl}$ and $1 \%$ of sodium or calcium nitrite. The best inhibiting capacity was noted when the inhibitor was introduced in the solution before the contamination with chlorides, what gave a reduced effect especially when chlorides were present in the simulated pore solution [Benzina et al, 2008] [7]. In salt solution the AMAbased inhibitor delayed the initiation of corrosion and reduced the Icorr (when the $\mathrm{NaCl}$ concentration is $0.3 \%$, Icorr was 0.45 and $0.1 \mu \mathrm{A} / \mathrm{cm}^{2}$ for the control and the inhibitor samples, respectively) [Heiyantuduwa et al,2003] [8]. AMA inhibitors are best used to extend (or help to achieve) the required service life by deferring the initial time to depassivation, and/or through reducing the rate of corrosion once corrosion is propagated, or retard incipient action (ring anode) [9]. Passivation due to the amino inhibitor is reached by the formation of an adsorbed layer on the steel surface. When the critical concentration ratio is not reached, the layer is partly destroyed, and the corrosion damage is rather localized. When the stabilization of the passive state is reached due to the inhibitor and subsequently the 
concentration of the inhibitor is reduced, the initiation of corrosion might reoccur (the ratio of concentrations inhibitor/ $\mathrm{Cl}^{-}$is critical also in such cases) [10]. The sooner the inhibitor is introduced after corrosion propagation the more effective it is [11]. The long-term concentration of the inhibitor near the reinforcement, which may decrease over time due to leaching and evaporation, is a crucial parameter for the effectiveness of the inhibitor as part of a repair strategy [12]. Monoflurophosphate seems slightly efficient in simulated pore solution and in mortar and higher MFP concentration being slightly better (0.05, 0.1 and $0.5 \mathrm{M}$ MFP and $0.5 \mathrm{M} \mathrm{NaCl}$ ) [Alonso, 1996] [13]. The effectiveness of MFP increases with the inhibitor concentration in alkaline solution [Hope and Thompson, 1995] [14] and the minimum efficient ratio $\mathrm{MFP} / \mathrm{Cl}^{-}(0.5 \mathrm{M} \mathrm{NaCl}$ and $0.5 \mathrm{M} \mathrm{MFP})$ is reported to be 1-1.5 [Lafave et al, 2002, Palmer and Malric, 2000] [15,16].The aim of this work is study of the basic mechanism of inhibitors for corrosion control of reinforcement in concrete by tests in simulated concrete pore solution.

\section{Experimental program}

This part consists of two methods based on influence of (CNI, AMA and MFP) inhibitors firstly, in simulated concrete pore solution and secondly, influence of AMA in extracted cement solution because AMA is claimed to inhibit corrosion by penetrating concrete and adsorbing on the metal surface more than CNI and MFP. The demonstrate AMA in extracted cement solution is new applied to evaluate the influence of inhibitors in blended cement extract solution. The laboratory tests in simulated concrete pore solution included exposure of steel specimens in pore solution with analysis of corrosion damage and passive layers; exposure of steel specimens in pore solution with chloride and analysis of corrosion damage; determination of potentiodynamic polarization curves in simulated pore solution; determination of electrochemical impedance spectra in simulated pore solution. 


\subsection{Materials and methods}

108 In order to achieve the goals of this study several laboratory tests in simulated concrete pore

109 solution were performed. These were as follows:

110 - Exposure of steel specimens in solution with analysis of corrosion damage and passive 111 layers,

112 - Exposure of steel specimens in artificial pore solutions with $\mathrm{Cl}^{-}$and analysis of corrosion 113 damage,

114 - Determination of open circuit potential $\mathrm{E}_{\mathrm{OC}}$, potentiodynamic polarization curves in 115 simulated pore solution,

116 - Determination of electrochemical impedance spectra in simulated pore solution,

117 - Influence of AMA inhibitors in blended cement extract solution

118 Corrosion inhibitors, CNI, AMA and MFP were added to the different solutions 119 separately. The dosage of CNI is $300 \mathrm{ml} / \mathrm{l}$ and the dosage of AMA is $4 \%(\mathrm{v} / \mathrm{v})$ which is 120 equivalent to $(40 \mathrm{ml} / \mathrm{l})$. In this work the dosage of MFP is $2 \%$ equivalent to $(20 \mathrm{~g} / \mathrm{l})$ and which 121 is below the recommended amount (5\%) to check the inhibition effect in the corrosion 122 process. Experiments were conducted using carbon steel bars, and with a diameter of $8 \mathrm{~mm}$ ), 123 reference steel. The inhibited steel surface was approximated as a cylinder with a height of 2

$124 \mathrm{~cm}$ corresponding to a surface area of $5.02 \mathrm{~cm}^{2}$. Each sample was allowed a period of 24 125 hours to stabilize in the solution before applying the test. Firstly, a saturated calcium 126 hydroxide solution (noted S1) has been used to simulate the aqueous alkaline content of the 127 (non-carbonated) concrete pore solution, with an approximate $\mathrm{pH}$ of 13. Secondly to 128 simulate the aqueous phase of a concrete contaminated with chloride, was used to obtain 129 an electrolyte designated by S2 (see Table 1). This contains $\mathrm{Ca}(\mathrm{OH})_{2}$ saturated solution and

$130 \mathrm{NaCl}$. This chloride content is higher than critical threshold by approximately 20 times,

131 because most of the existing research generally agrees that the $\mathrm{Cl}^{-} / \mathrm{OH}^{-}$threshold ratio for 
132 carbon steel is $<1$.The initial $\mathrm{pH}$ measured was 13 , but, it dropped to a value of $12.5 \pm 0.05$

133 due to the chloride addition and possible carbonation from air during poring into the

134 corrosion cells (Nedal, 2009) [17]. The range was 3.5\% for chloride concentration. In some

135 experiments the inhibitor was added to the simulated pore solution (S1) at the very beginning,

136 when the steel surface was still clean, to investigate delay of time to depassivation. In other

137 experiments the inhibitor was added the simulated pore solution (S2) after the corrosion

138 already started to investigate the influence on corrosion rate control. The results of the

139 measurements obtained in simulated pore solution represent the basis for further

140 investigations in concrete.

\section{$141 \quad 2.2 \quad$ Extracted cement solution}

142 This part is concentrated on the influence of AMA in extracted cement solution. Pore solution

143 extract for a concrete mix of water to cement ratio of 0.4 is $\left(\mathrm{Hydroxyl} \mathrm{OH}^{-}, 700 \mathrm{mmol}\right.$,

144 Sodium $\mathrm{Na}^{+}, 192 \mathrm{mmol}$, Potassium K $\mathrm{K}^{+}, 592 \mathrm{mmol}$, Sulphate $\mathrm{SO}^{-2}, 44 \mathrm{mmol}$, Calcium $\mathrm{Ca}^{+2}$,

$1452 \mathrm{mmol}$ ). The $\mathrm{pH}$ found in extracted cement solution is 13.7. The use of AMA in extracted

146 cement solution is new applied in our laboratory. The inhibition efficiency of the AMA to the

147 surface of six steel (repeatability for one test) placed in extract solutions more or less

148 corrosive and simulating more or less degraded concrete was investigated through

149 electrochemical methods Figures (1). Free corrosion potential measuring $\mathrm{E}_{\mathrm{OC}}$, Cyclic

150 polarization test and potentiodynamic scan (GC) were applied after 1 day and 2days up to 8

151 days of immersion. Experiments were conducted using carbon steel bars, and with a diameter

152 of $8 \mathrm{~mm})$, reference steel.

\subsection{Electrochemical Measurements}

155 In order to apply the open circuit potential (Eoc) of a metal, the potentiodynamic scan or the

156 cyclic polarization scan, three electrodes are immersed in the testing solution and connected 
to a Biologic Ec- Lab potentiostat a device that is used to apply on over potential and record

158 the induced current. Potentiodynamic scan and cyclic polarization are similar to the Cyclic

159 polarization test. These tests were applied after 1 day and 2 days up to 8 days of immersion.

160 The data obtained for each time from six steel (repeatability for one test). The electrochemical

161 impedance is then automatically calculated from this data in lab measurements. The

162 experiment is controlled by data logging system and analysis is done using software provided

163 by the manufacturer.

164

165

166

167

168

169

170

171

172

173

174

175

176

177

178

179

180

181

\subsubsection{Open Circuit Potential Measurements EOC}

The free corrosion potential is a good indication of the metal's tendency to corrode in a certain solution. Having a relatively fixed (not drifting) potential is an indication that the sample has stabilized in the solution. The test parameters are:

- The total time: this is the test duration in seconds. The sample's potential was measured against the Saturated Calomel Electrode (SCE) for duration of 60 seconds.

- The sample period: this parameter determines the spacing between data points in seconds. The sample period was 1 second.

- The stability: that is used to tell the system the definition of a stable potential. When measuring the open circuit potential, if the drifting rate falls below the stability this will result in terminating the experiment immediately. This parameter has units of $\mathrm{mV} / \mathrm{sec}$. The stability was set to be zero $\mathrm{mV} / \mathrm{sec}$. This means that the test will be terminated only when the total time ends.

- Sample Area: the sample surface area in $\left(\mathrm{cm}^{2}\right)$ that is immersed in the solution.

\subsection{2 . Potentiodynamic Scans}

The potentiodynamic scan was used to measure corrosion current density, and then corrosion rate was calculated. For every sample, the potentiodynamic scan was applied to determine the corrosion current density icorr at that time. The test parameters are: 
182

183

184

185

186

187

188

189

190

191 period. The applied scan rate was $0.1 \mathrm{mV} / \mathrm{sec}$.

192 +Density: is the density of the metal tested in $\mathrm{g} / \mathrm{cm}^{3}$. This parameter is used for corrosion rate 193 calculation.

194

-Initial E: is the starting point for the potential sweep in Volts. The initial potential E was -100 mV vs. $E_{\text {OC }}$.

-Final E: is the ending point for the potential sweep in Volts. The final potential E was 1000 $\mathrm{mV}$ vs. $\mathrm{E}_{\mathrm{OC}}$. This scan range $\left(\mathrm{E}_{\mathrm{OC}}\right.$ from -100 to $\left.+1000 \mathrm{mV}\right)$ enabled the estimation of icorr without destroying the sample. Testing further anodic potentials would force the sample to corrode (i.e., destructive testing).

-The sample period: the sample period was 1 second.

-Scan Rate: is the speed of the potential sweep during data acquisition. Its unit is $\mathrm{mV} / \mathrm{sec}$. Very high scan rates lead to unreliable data; however, very low scan rate elongate the test calculation.

-Equivalent Weight: is the theoretical mass of metal that will be lost from the sample after one Faraday of anodic charge has been passed. This parameter is used in corrosion rate calculations.

-Initial Delay: this option is used to allow the open circuit potential of the sample to stabilize prior to the potential scan. The delay time is the time that the sample will be held at its open circuit potential $\mathrm{E}_{\mathrm{OC}}$ prior to the scan. The delay may stop prior to the delay time if the stability criterion for $\mathrm{E}_{\mathrm{OC}}$ is met. The delay time parameter is active only if the initial delay is turned on. This option was turned off in all the experiments.

-Extrapolation of the corrosion current density icorr was made with the help of potentiostat Analyst software.

\subsubsection{Cyclic polarization}

Each sample was allowed a period of 24 hours to stabilize in the solution before applying the test. The test parameters are: 
-Initial E: is the starting point for potential sweep; initial Ewas $-0.025 \mathrm{~V}$ vs. $\mathrm{E}_{\mathrm{OC}}$.

-Final E: is the ending point for potential sweep; final $\mathrm{E}$ was $+0.025 \mathrm{~V}$. The forward scan rate was $0.5 \mathrm{mV} / \mathrm{sec}$. The test is used mainly to investigate the metal ${ }^{\text {ee }} \mathrm{s}$ tendency to pitting corrosion in a certain environment and this ratio may be reach to $-600 \mathrm{mmV}$ to +600 $\mathrm{mmV}$ according to aggressive environment.

-Apex E: is the end potential for the anodic (upward) scan. Apex E (Erev) is one of two 213 conditions that will terminate the forward sweep and initiate the reversal scan if it is reached and the Apex I is not exceeded yet. Apex E was one V vs. $\mathrm{E}_{\mathrm{OC}}$.

-Apex I: is the corrosion current density that is indicative of pitting initiation and it is one of two conditions that will terminate the forward sweep and initiate the reversal scan if it is exceeded by the absolute current of the sample. The Apex I was $1 \mu \mathrm{A} / \mathrm{cm}^{2}$.

\subsubsection{Electrochemical Impedance Spectroscopy (EIS):}

Literature on the applications of EIS shows that it has great advantages over other techniques in studying the passive film formation providing the use of low frequencies of AC signal [Pruckner, 2001] [18]. The test parameters are:

Initial Frequency: is the starting point for the frequency sweep during the data acquisition phase. The frequency unit is Hertz. The initial frequency was $100 \mathrm{kHz}$.

Final Frequency: is the ending point for the frequency sweep during the data acquisition phase. The final frequency was $100 \mathrm{mHz}$ for cathodic electrochemical treatment and $50 \mathrm{mHz}$

227 for inhibitor treatment. Testing lower frequencies would make the test duration too long.

228 Points/decade: is the number of data points in each decade frequency. The value used was the 229 default value of $70-90$ points per decade.

230 AC Voltage: is the amplitude of the applied AC (alternated current) signal to the working 231 electrode. The unit is in root mean square (rms) $\mathrm{mV}$. The excitation AC signal should be 232 small in order to keep in the linear region (i.e., the AC current response will be in the same 
233 frequency but with phase shift) and not to destroy the sample. The applied AC voltage was 10 $234 \mathrm{mV}$ rms.

235 DC Voltage: is the applied DC (direct current) voltage on the working electrode. The purpose 236 of the experiment was to study the properties of the passive film that is formed naturally on 237 the metal surface. Thus, samples were held at their free corrosion potential EOC (i.e., DC 238 Voltage $=0.0$ vs. EOC).

239 Estimated Z: is a rough estimate of the cell's impedance at the Initial Frequency entered. This 240 value is used to minimize the number of trials that the

241 system operates to calculate the cell's impedance at the first data point. After the first point, 242 this value is not important as the system uses the last estimated value for $\mathrm{Z}$ to calculate the 243 new Impedance with the new frequency.

244 Figure 2a shows a schematic of the equivalent circuit $\mathrm{R}(\mathrm{QR})$ for non treated steel used in EIS 245 data fitting. The proposed electric equivalent circuit $\mathrm{Rel}+\mathrm{Cf} / \mathrm{Rf}+\mathrm{Cdl} / \mathrm{Rct}$ for steel treated with 246 inhibitors by [Nedal, 2009 and Pruckner $2001[17,18]$ in their work to study passive film 247 formation on carbon steel in alkaline solutions is given in Figure 2b. This circuit consists of 248 the solution ohmic resistance Rel connected in series to two loops. The first loop represents 249 the double layer capacitance $\mathrm{Cdl}$ and the charge transfer resistance Rct. The other loop represents the passive film formed on steel surface in the high alkaline solutions where $\mathrm{Cf}$ and

$251 \mathrm{Rf}$ are the faradic capacitance and the ohmic resistance of the film, respectively. It is believed 252 that this circuit introduces a reasonable explanation of the ongoing electrochemical process on 253 the metal surface immersed in a high alkaline solution.

254 Since the capacitance (c) equals the charge built up in the capacitor (q) divided by the 255 potential (V) (the free corrosion potential in this case), a metal in a passive state (i.e. less metal dissolution-less charge transfer between the metal surface and the electrolyte) will have 257 less capacitance than an actively corroding metal. In other words, for a constant exposed area 
an active corrosion process will lead to an increase in the total charge transfer, which leads to

259 increased film capacitance [Nedal, 2009, Sahoo and Balasubramaniam 2008] [17, 19].

260 This electrochemical impedance of the system presented in the following equations.

261 The impedance $\mathrm{Z}$ of a resistor equals:

$262 \mathrm{Z}=\mathrm{R}$

263 Where $\mathrm{R}$ is the resistance in ohms. The impedance of a capacitor equals:

$264 \quad Z=\frac{1}{J W C}$

265 Where $\mathrm{C}$ is the capacitance in farads, $\mathrm{j}$ is $\sqrt{-1}$ and $\mathrm{w}$ is the angular frequency $\mathrm{w}=2 \pi \mathrm{f}$.

266 The total impedance of a system Ztotal when the components are connected in series equals:

$267 \quad$ Ztotal $=\mathrm{Z} 1+\mathrm{Z} 2$

268 The total impedance of a system Ztotal when the components are connected in parallel equals:

$\mathrm{Z}_{\mathrm{total}}=\frac{\mathrm{Z}_{1} \mathrm{Z}_{2}}{\mathrm{Z}_{1}+\mathrm{Z}_{2}}$

270 Thus, the total impedance equals:

$$
\mathrm{Z}_{\text {total }}=\mathrm{R}_{\mathrm{el}}+\frac{\mathrm{R}_{\mathrm{f}}}{1+\mathrm{R}_{\mathrm{f}}\left(\mathrm{j} \cdot \mathrm{w} \cdot \mathrm{C}_{\mathrm{f}}\right)}+\frac{\mathrm{R}_{\mathrm{ct}}}{1+\mathrm{R}_{\mathrm{ct}}\left(\mathrm{j} \cdot \mathrm{w} \cdot \mathrm{C}_{\mathrm{dl}}\right)}
$$

272 Where

273 Rel: resistance of electrolyte

274 Rf: film resistance formed in alkaline solution

275 Rct: charge transfere resistance

276 The other loop represents the passive film formed on steel surface in the high alkaline

277 solutions where $\mathrm{Cf}$ and $\mathrm{Rf}$ are the faradic capacitance and the ohmic resistance of the film, 278 respectively.

279 A capacity film reduction (Cf) that leads to a film thickness increase (equation (5.6)) 280 expressed as $\mathrm{C}_{\mathrm{f}}=\varepsilon_{\circ} \varepsilon_{\mathrm{r}} \mathrm{A} / \mathrm{d}$ 
281 Where $\varepsilon_{\mathrm{O}}$ is the vacuum permittivity $(8.85 \times 10-14 \mathrm{~F} \mathrm{~cm}-1), \varepsilon_{\mathrm{r}}$ is the dielectric constant $282(\approx 1)$, A the active surface and $\mathrm{d}$ the thickness of film.

$2832.4 \quad$ SEM and EDS analysis.

284 To characterize the influence of coating in protection of steel from corrosion, SEM reveals the 285 morphology and composition of film on the surface of steel created by inhibitive treatments in 286 simulated concrete pore solution. The overall analysis SEM and EDS has identified the 287 elements on surface of steel treated by inhibitors.

\section{Results and discussion}

3.1 Results of Carbon Steel Immersed in Synthetic Solutions Emulating Concrete Admixed with Inhibitors Open circuit potential.

\subsubsection{Open circuit potential}

293 Fig. 3 shows the open circuit potential (also referred to the rest potentials) test obtained from 294 linear polarizaton tests for carbon steel samples immersed in synthetic concrete pore solutions S1 as after 1 hour, untel 8 days of immersion. Each point in this figure is the average of six points. At the first hours of the addition of inhibitors the rest potentials $\mathrm{E}_{\mathrm{OC}}$ are respectively around $-100 \mathrm{mV}$ for the CNI,-460 for MFP in comparison with $\mathrm{S} 1$ without inhibitors and $330 \mathrm{mV}$ for AMA. Guidance for interpretation of results is given in the ASTM standard

C876-99[20] and is summarized in Table 2. The systems showing potentials lesser negative than-276 $\mathrm{mV}$ versus SCE are treated as passive systems and systems showing more negative than $-276 \mathrm{mV}$ versus SCE are treated as active. Thus, the rebars in S1+ CNI are probably passive whereas an active corrosion probably takes place on the rebars in S1 without inhibitor and with MFP.The rest potentials increase with time. Eight days after addition of inhibitors,

304 the rest potentials EOC of S1+CNI are respectively between -50 and $-20 \mathrm{mV}$ and between 220 and $-330 \mathrm{mV}$ for all inhibitors added in S1. These results indicate adsorption of an inhibitor film on the iron surface which leads to a slowdown of the corrosion probability after 
the inhibitor addition. The potential of steel without inhibitors increases due to the presence of

308 passive layer of oxides $\left(\mathrm{Fe}_{3} \mathrm{O}_{4}\right.$ and $\left.\mathrm{Fe}_{2} \mathrm{O}_{3}\right)$ on the surface of steel.

\subsubsection{Corrosion current evolution}

310 The corrosion currents obtained from applying cyclic polarization curves for S1+CNI, 311 S1+AMA and S1+MFP are illustrated in Figure 4. According to RILEM studies [Andrade et 312 al. 2004] [21], 4 ranges of corrosion activity can be distinguished from negligible, to weak, to 313 moderate and up to high Table.3. Each point of the corrosion current in this figure is the 314 average of six points. After addition of inhibitor, the data shows lower corrosion currents with 315 time and after 8 days the corrosion current range is from 0.12 to $0.46 \mu \mathrm{A} / \mathrm{cm}^{2}$ for $\mathrm{S} 1+\mathrm{CNI}$, S1+AMA respectively. For rebar S1+MFP, corrosion activity after 8 days is $\left(3.5 \mu \mathrm{A} / \mathrm{cm}^{2}\right)$. In cases, S1+CNI, S1+AMA, the corrosion activity is constant with time. For S1 without inhibitor and MFP the current also is almost constant and more than $1 \mu \mathrm{A} / \mathrm{cm}^{2}$ corresponding to high rate corrosion. So the corrosion process is probably slowed down but not stopped with $\mathrm{S} 1+\mathrm{MFP}$. The order of Icorr from high to weak is: $\mathrm{S} 1=\mathrm{S} 1+\mathrm{MFP}, \mathrm{S} 1+\mathrm{AMA}>\mathrm{S} 1+\mathrm{CNI}$.

\subsubsection{EIS measurements in pore solution}

322 The electrical parameters $\left(\mathrm{C}_{\mathrm{dl}}, \mathrm{Rc}_{\mathrm{t}}\right)$ obtained through fitting EIS data, using the electric equivalent circuit $\mathrm{R}(\mathrm{QR})$ and $\mathrm{R}_{\mathrm{el}}+\mathrm{C}_{\mathrm{f}} /\left(\mathrm{R}_{\mathrm{f}}+\mathrm{C}_{\mathrm{d} /} / \mathrm{R}_{\mathrm{ct}}\right)$, are listed in (Table 4). The values of Epit in table 4 illustrate that inhibitors increase the pitting resistance of the metal. EC-Lab software was used in data fitting. The mathematical method used was Levenberg- Marquardt method.

326 Figure 5 shows a Nyquist plot of the impedance of carbon steel immersed in fresh concrete 327 pore solution with various amounts of inhibitors added to the solution in a period of 8 days. It can be noticed that the low frequency portion of the impedance spectra (on the right hand side) increases with presence of inhibitor in the solution as a sign of passivity does not break down. Figure 5 shows the main conclusions for all types of inhibitors, the order of inhibition is: $\mathrm{S} 1+\mathrm{AMA}>\mathrm{S} 1+\mathrm{CNI}>\mathrm{S} 1+\mathrm{MFP}>\mathrm{S} 1$ according to the values of $\mathrm{R}_{\mathrm{ct}}$. 
332 In the Nyquist impedance two time constants (one at high frequency HF and another at low

333 frequency LF) for treated steel, and thus the capacitive loop observed in the Nyquist plots is 334 consisted of two non-decoupled capacitive loops just for CNI. For the carbon steel film, the 335 double layer capacitance $\mathrm{C}_{\mathrm{dl}}<2.5 \mu \mathrm{F} / \mathrm{cm}^{2}$ shows that a small part $\mathrm{R}_{\mathrm{ct}}$ of the inhibited steel 336 surface is involved in the electrochemical reactions at the steel/solution interface [Simescu 337 and Idrissi, 2009] [22]. The corrosion reaction occurs only on a very small fraction of the total 338 inhibitor steel area.

339 Basically, the passive film has a high resistivity with inhibitors; however, it decreased with 340 reference specimens in the solution S1. The inhibitor layer of iron oxides/hydroxides surface 341 film seems to cover the entire surface blocking the active sites and the total impedance of the 342 system increases continuously. Thus, the increase in the sum of the charge transfer resistance 343 and the film resistance $\left(\mathrm{R}_{\mathrm{ct}}+\mathrm{R}_{\mathrm{f}}\right)$ was observed in Table 4 . The faradic capacitance of the 344 passive film $\mathrm{Cf}$ decreased with inhibitors addition to the solution due to the decrease of charge 345 transfer at the metal/electrolyte interface and reduction of capacity film $\left(\mathrm{C}_{\mathrm{f}}\right)$ that leads to a 346 film thickness increase. It is remarkable that the film capacitance MFP decreased by about six 347 times than AMA and by three times than CNI. $\mathrm{R}_{\mathrm{f}}$ and $\mathrm{C}_{\mathrm{f}}$ are absent in diagrams corresponding 348 to reference specimens immersed in alkaline solution, during only 8 days, due to the 8 days is 349 not enough formation film on the surface of steel and also absence of inhibitors.

\subsubsection{Cyclic polarization curve}

351 It can be noticed that the metal had a passive region (decreased applied over potential and 352 current density) that started immediately after the Tafel area $\left(\mathrm{E}_{\mathrm{OC}} \pm 50 \mathrm{mV}\right)$ for $\mathrm{CNI}$ and 353 between -220 and $-400 \mathrm{mV}$ for all inhibitors added in $\mathrm{S} 1$ and continued until $\mathrm{E}_{\text {pit }}$ was reached 354 Figure 6. The results of $\mathrm{E}_{\mathrm{pit}}$ are shown in Table 4. In these solutions, the hysteresis loop was 355 determined but Erev seems adherent because corrosion inhibitors are not used to totally stop corrosionand $\mathrm{E}_{\mathrm{pit}}$, which is an indication that the metal is repassivate and able to resist pitting 
corrosion at these inhibitors types. In addition, the recorded $i_{\text {corr }}$ of MFP in reverse scan is higher than other inhibitors. Perhaps a longer exposure time in that solution with MFP was needed to increase the pitting resistance of the metal.

\subsubsection{Surface analysis with SEM}

a). SEM of carbon steel in $S 1+M F P$

Figure $7 \mathrm{~b}$ shows the SEM on the surface of the samples immersed during 1 week in solutions S1 with MFP inhibitor. The inhibiting action of sodium phosphate showed that phosphate compounds form a protective layer on the steel surface when immersed in alkaline solution without chlorides. A passive layer of $\mathrm{Fe}_{3} \mathrm{O}_{4}, \gamma \mathrm{Fe}_{2} \mathrm{O}_{3}$ and $\mathrm{FePO}_{4} . \mathrm{H}_{2} \mathrm{O}$ results of hydrolysis $\mathrm{Na}_{2} \mathrm{PO}_{3} \mathrm{~F}$ in aqueous and neutral media to form orthophosphate and fluoride [Alonso et al, 1996] [13]. But phosphate compounds characterized by spherical glassy plate of sand rose, lamellar shapes crystal exists on the surface of steel.

\section{b). SEM of carbon steel in $S 1+A M A$}

The surface of the samples immersed during 1 week in solutions with inhibitor is depicted in Figure 7c. The one zoom images shows the presence of an oxide film due to displacement of the first hydrated monolayers of the iron oxide film. Smialowska et al (1981) [23] on the other hand, showed that the passive films formed in alkaline solutions are closer to an iron oxihydroxide $(\mathrm{FeOOH})$ than to $\gamma-\mathrm{Fe}_{3} \mathrm{O}_{4}$ or $\mathrm{Fe}_{2} \mathrm{O}_{3}$ Smialowska et al (1985) [24]. The uniform film deposited over the surface and practically there are no signs of corrosion. The film becomes much thicker, more uniform and amino compounds are present on its surface. This behaviour is according to the literature, which suggests that the organic inhibitors usually adsorb on the surface leading to the formation of a thin adsorbed layer [Jamil et al. 2003] [25]. The SEM observations show that the (N-CH bonds) is compact well crystallized and covers completely the steel surface. The film observed in big area characterized by eggs shape or cotton-balls shaped due to its big thickness. These positive charged groups are likely to form 
382 at the expense of inhibitor interaction with water molecules (from hydrated layers

383 compounds) on the iron surface [Jamil et al, 2003] [25]..

c). SEM of carbon steel in $S 1+C N I$

385 The results of influence of CNI on microstructure are shown in Figure $7 \mathrm{~d}$. A stable passive 386 layer of $\gamma-\mathrm{FeOOH}$ is formed on the surface of steel. This film is insoluble in aqueous alkaline 387 solution and creates a solid layer on steel surface blocking the transport of ferrous ions into 388 the electrolyte. As can be seens from Figure $7 \mathrm{~d}$ mixture of flower-like pattern of $\alpha-\mathrm{FeOOH}$ 389 (goethite) and $\gamma$-FeOOH (lepidocrocite) and plate-shaped of calcium hydroxide are 390 presented[So“ylev and Richardson, 2008] [26]. The inner layer composed mainly of magnetite 391 is compact, dense and adherent.

392 Results of Carbon Steel Immersed in Synthetic Solutions Emulating Concrete Admixed with 393 Inhibitors Open circuit potential

3.2 Results of Carbon Steel Immersed in Synthetic Solutions Emulating Concrete Admixed with Inhibitors under Chloride Ion Attack.

\subsubsection{Open circuit potential}

397 Figure 8 shows the open circuit potential in case of pore solution admixed with inhibitors 398 under amount of chlorides $35 \mathrm{~g} / \mathrm{l}$. The rest potential value for S2 decreases significantly after 3998 days (due to the presence of chloride). A drop in the corrosion potential was happened by 400 other researchers as an indication of reaching the critical chloride limit [Hausmann, 1967 and $401 \mathrm{Li}$ and Sagues, 2001] [27,28]. For S2+MFP and S2+AMA the rest potential has 402 approximately the same value and increases with time. This result due to two reasons: the first 403 reason is the competition between chloride and the film of inhibitor which leads to increase 404 resistivity of the film the second reason is that protonated amino group's bind chloride so the 405 concentration of chloride required for initiation of corrosion. This is an important feature 406 when the inhibitor is used in concrete structures, since it may help to increase the $\mathrm{Cl}^{-} / \mathrm{OH}^{-}$ 407 threshold ratio, which is one of the more important parameters in controlling the corrosion in 
408 reinforced concrete structures [Jamil et al, 2003] [25]. AMA is recommended as

409 complementary technique for reduction in time of regeneration of the passivity is obtained.

$410 \mathrm{CNI}$ is not affected by presence of chloride see Figure 8

\subsubsection{Corrosion current evolution}

412 Figure 9 shows the corrosion current density ( $i_{\text {corr }}$ ) obtained from carbon steel samples

413 immersed in S2. With time, the corrosion currents for S2+CNI remain low and closed to 414 values obtained with no chloride. The previous result indicates that calcium nitrite not 415 affected by the presence of chloride and this du to that nitrite does not incorporate into the 416 passive film, but reacts with the anodic corrosion products in the early stage competing with 417 the chloride ions and hydroxide ions. It helps to repair the flaws, which are caused by chloride 418 dissolution of the oxide film to the soluble chloro complexes of iron [El-Jazairi and Berke, 4191992 and Berke and Weil, 1994] [29,30]. But S2+AMA and S2+MFP show corrosion current 420 which is decreasing with time and ranging from 2.5 to $7.5 \mu \mathrm{A} / \mathrm{cm}^{2}$ at 8 days, indicating a 421 lower corrosion activity of the rebars. Each sample needs enough time to whether develop its 422 passivation layer or actively corrode. For S2, the corrosion currents of rebars increase significantly with time because of the corrosion products.

\subsubsection{EIS measurements in pore solution (Initiation of corrosion (prevention of} corrosion))

427 In this group of experiments the inhibitor was firstly added to the pure simulated pore 428 solution, and afterward chlorides were successively added. The main goal of these experiments was to investigate whether the inhibitor additionally stabilizes the passive state of

430 clean, already passivated steel surface. At the beginning, it can be seen in Figure 10 that the 431 inhibitor increased the total electro-chemical impedance of the system, as well as changed the 432 profile of the spectra. The significant reduction of the total impedance was observed when the 
433 chloride concentration in pore solution reached a rather high value. From the measured

434 spectra presented as Nyquist plots it can be seen that the inhibitor considerably changed the

435 shape of the spectrum. It can be therefore concluded that the structure of the passive layer due

436 to the inhibitor differs from the layer in pure pore solution. The electrical parameters are listed

437 in (Table 5) at 8 days. EIS data for S2 containing CNI, AMA and MFP aged 8 days in the

438 same aggressive solution. Calcium nitrite is an anodic inhibitor. It functions by oxidizing

439 corrosion product - ferrous ions - to ferric ions that precipitate in the alkaline solution of the

440 concrete and form a protective layer on the reinforcement. The precipitate functions as a film

441 repair because the ferric ions are insoluble in aqueous alkaline solutions and block the transfer

442 of ferrous ions into the electrolyte. This is data due to competition between the formation and

443 local destruction of the film obtained by the slow inhibitor dissolution. This classical

444 corrosion mechanism leads to the diminution of $\mathrm{R}_{\mathrm{ct}}$ and to the increase of the double layer 445 capacitance $C_{d l}$ while $R_{f}$ increases in comparison with $S 1$. This evolution corresponds to the 446 electrolyte diffusion into the film pores. The order of inhibition is: $\mathrm{S} 2+\mathrm{CNI}>\mathrm{S} 2+\mathrm{AMA}$ $447>\mathrm{S} 2+\mathrm{MFP}>\mathrm{S} 2$ according to the values of $\mathrm{R}_{\mathrm{ct}}$.

\subsubsection{Cyclic polarization curve}

450 Figure 11 represent the potentiodynamic polarization curves of steel in S2 solution without 451 and with CNI, AMA and MFP. A higher significant potential shift is observed between S2 452 with inhibitor and the S2 without inhibitor. It can be noticed that the pitting potential for CNI 453 equal to $+200 \mathrm{mV}$ vs. SCE and this help the metal to repassivate (heal) when the pitting 454 potential is increase.

455 The increase of the passive current density for the film resistance is suggesting the presence 456 of a protective homogeneous layer on the steel surface. S2+MFP lead to the anodic formation 457 of a passive layer which contributes to the decrease of chloride aggressiveness. A drop in 
458 polarization resistance is an indication of reaching the critical chloride limit [Trejo and Pillai, 4592004 and Qian et al., 2008] [31,32].

460 Perhaps a longer exposure time of MFP in the solution S2 was needed to increase the pitting 461 resistance of the metal. At higher chloride concentrations of reference specimen S2, the 462 pitting potential $\mathrm{E}_{\mathrm{pit}}$ decreased to be $-400 \mathrm{mV}$ vs. SCE, and the hysteresis loop did not close. 463 The results of $\mathrm{E}_{\mathrm{pit}}$ are shown in Table 5. This is an indication of the breakdown of the passive 464 film and that the metal was not able to repassivate (was not able to heal) at these chloride concentrations. This behaviour can be explained by the competitive action of both $\mathrm{Cl}^{-}$and $\mathrm{OH}^{-}$ions in the solution [Naceur et al, 2007] [33].

\subsubsection{The charge transfer and film resistance}

Figure 12 and Figure 13 show an increase in the charge transfer resistance $\left(\mathrm{R}_{\mathrm{ct}}\right)$ and film resistance $\left(\mathrm{R}_{\mathrm{f}}\right)$ for all inhibitor more than the refrence. However, $\mathrm{R}_{\mathrm{f}}$ is equal to zero in Ref steel due to absence of inhibitors even with and without of $\mathrm{Cl}^{-}$ions in the solution, this behaviour may be due to the time (8days) no sufficint for formation of film on the surface of steel. The order of inhibition when immersed in S1 is: AMA >CNI >MFP > Ref steel according to the values of Rct, this meaning that AMA is more active in absence of chloride. The order of inhibition is: CNI $>$ AMA $>$ MFP $>$ Ref steel according to the values of $\mathrm{R}_{\mathrm{ct}}$ and $\mathrm{R}_{\mathrm{f}}$ when immersed in $\mathrm{S} 2$, this meaning that $\mathrm{CNI}$ is more active in presence of chloride. Basically, the passive film has a higher resistivity with CNI, AMA and MFP than the reference in pore solution $\mathrm{S} 2$ due to competition between chloride and the film of inhibitors which act as mechanical barrier against corrosion. MFP seems slightly efficient in simulated pore solution and slightly lower with $\mathrm{NaCl}$.

\subsubsection{Surface analysis with SEM}

\section{a). SEM of carbon steel in $S 2+M F P$}


483

484

485

The SEM shows that the pitting was observed on the sample Figure 14b. The brighter surface in SEM microphotographs exhibit pits that appeared darker in optical microphotographs. The pits appeared to occur only on sharply faceted grains. This indicates the accumulation of salts of phosphorus, chloride and calcium in the pits. The cracks have higher phosphorus content and exhibited the deposition of corrosion products.

\section{b). SEM of carbon steel in $S 2+A M A$}

In figure $14 \mathrm{c}$ the SEM observations show the presence of a great amount of corrosion products like balloons swell and spread over the entire layers of the film surface.

It is suggested [Smialowska et al.1985 and 1981] [23,24] that the presence of chlorides in the solution changes the composition, thickness, and density of the passive film. Some author's report that the film formed in the presence of chlorides becomes thicker, but more porous and hydrated, loosing its protective character [Jamil HE et al. 2005] [34].

The negatively charged ions (chloride ion) could reflect an interaction with the protonated amino groups.

\section{c). SEM of carbon steel in $S 2+C N I$}

In figure $14 \mathrm{~d}$ the SEM observations show the presence of a white precipitate formed over surface. This precipitate was analysed using EDS (X-ray spectroscopy) and found to be predominantly calcium and oxygen, suggesting that it is most likely $\mathrm{Ca}(\mathrm{OH})_{2}$. However, full protection depends greatly on the concentration of aggressive ions such as the chloride ion. The free chloride concentration in the pore solution admixed with CNI decreased and the $\mathrm{OH}^{-}$ content increased with the time of aging.

$\mathrm{CNI}$ is highly soluble in neutral solution. However, in solutions of very high $\mathrm{pH}$ value the concentration of $\mathrm{Ca}^{2+}$ ions is strongly limited by the solubility product of $\mathrm{Ca}(\mathrm{OH})_{2}$. The presence of $\mathrm{CN}$ in the pore solution causes part of its $\mathrm{Ca}^{2+}$ ions to react with the $\mathrm{OH}^{-}$ions in the solution to precipitate calcium hydroxide [Li et al, 2000] [5]. 
512 In the recent years, there are few studies using AMA in advanced types of blended cement

513 concrete. So this new study focused only on using ethanolamine in extract pore solution of blended cement.

\section{a). Open circuit potential}

517 Figure 15 shows the open circuit potential tests for carbon steel samples immersed in solution extract of cement without chloride (EC) and solution extract of cement with chloride $35 \mathrm{~g} / \mathrm{l}$ added to the solution (ECC). After 8 days the rest potentials $\mathrm{E}_{\mathrm{OC}}$ are almost constant with time respectively around $-250 \mathrm{mV}$ for the EC+AMA and $-330 \mathrm{mV}$ for EC. According to ASTM (C876) the rebars in EC+ AMA are probably passive. These results indicate adsorption of passive film on the iron surface.

523 For ECC, after eight days, the rest potential values are higher until 6 days then decrease. This 524 means that the corrosion conditions are in risk range.

\section{b). Corrosion current evolution}

The corrosion currents are illustrated in Figure 16. After addition of inhibitor, the data shows lower corrosion currents with time and after 8 days the corrosion current range is from 4.5 to $3.9 \mu \mathrm{A} / \mathrm{cm}^{2}$ for EC+AMA. It is to be noticed that this corrosion current constant with tendency of steel to corrod, which could be considered as an efficiency indicator for the

530 inhibitor treatment according to RILEM studies [Andrade et al. 2004] [21]. In case of EC and

531 EC+AMA the corrosion activity is constant. In case, of extract solution ECC without 532 inhibitor, under amount of chlorides $35 \mathrm{~g} / \mathrm{l}$ gives corrosion activity increase with time and 533 those obtained from extract solution with inhibitor ECC+AMA decrease due to presence of 534 amino inhibitors and this results agree with [Qian et al, 2008] [32]. The ECC behaviour can 
535 be explained by lowering of $\mathrm{pH}$ by competitive action of both $\mathrm{Cl}^{-}$and $\mathrm{OH}^{-}$ions in the solution 536 (see equation [8.3]).

$$
\mathrm{Fe}\left(\mathrm{Cl}_{6}\right)^{-3}+6 \mathrm{H}_{2} \mathrm{O}=\mathrm{Fe}(\mathrm{OH})_{3}+3 \mathrm{OH}+6 \mathrm{HCl}
$$

\section{c). EIS measurements in pore solution}

539 Figure 17 shows a Nyquist plot of the impedance for carbon steel samples immersed in 540 solution extract of cement with and without chloride in presence of AMA.

541 The electrical parameters obtained through fitting EIS data, using the electric equivalent 542 circuit $\mathrm{R}(\mathrm{QR})$ and $\mathrm{R}_{\mathrm{el}}+\mathrm{C}_{\mathrm{f}} /\left(\mathrm{R}_{\mathrm{f}}+\mathrm{C}_{\mathrm{dl}} / \mathrm{R}_{\mathrm{ct}}\right)$, are listed in Table 6. From these diagrams low values 543 of $\mathrm{C}_{\mathrm{f}}$ and $\mathrm{C}_{\mathrm{dl}}$ are recorded. The increase in the sum of the charge transfer resistance and the 544 film resistance $\left(\mathrm{R}_{\mathrm{ct}}+\mathrm{R}_{\mathrm{f}}\right)$ was observed was adding of AMA.

545 For ECC, an increase in the sum of the charge transfer resistance and the film resistance $\left(\mathrm{R}_{\mathrm{ct}}+\right.$ $546 \mathrm{R}_{\mathrm{f}}$ ) was observed with AMA. It is remarkable that the film capacitance of AMA increased by 547 about three times from the beginning in EC of the experiment AMA $\left(\mathrm{C}_{\mathrm{f}} 27.6 \mu \mathrm{F} / \mathrm{cm}^{2}\right)$ until a 548 chloride concentration in the solution ECC of $35 \mathrm{~g} / 1\left(\mathrm{C}_{\mathrm{f}} 80 \mu \mathrm{F} / \mathrm{cm}^{2}\right)$. AMA has great corrosion 549 protection ability although it induced more chloride ion into the OPC concrete than BCC. This 550 corrosion protection might be greatly attributed to the organic part in AMA around the rebar. 551 The low frequency portion of the impedance spectra decreases in solution extract of cement in 552 presence of chloride ion in the solution.

Conclusions

From the results presented in this paper it can be concluded that:

- Calcium nitrite (CNI), sodium monoflurophosphate (MFP) and ethanolamine (AMA) based inhibitors showed reductions in the overall rates of corrosion after the inhibitive treatments. 
- In alkaline solution with or without chloride, the CNI steel sample is more resistant than 561 carbon steel alone and causing passivation of steel in concrete. Thus, a dense and 562 protective layer is formed.

563 - The laboratory study in simulated pore solution proved that all tests in simulated concrete 564 pore solution proved that the amino alcohol inhibitor can reduce corrosion: the most 565 important parameter is the ratio of inhibitor/chloride concentration,

566 - if the steel reinforcement is heavily corroded the critical concentration ratio is strongly 567 dependent on the steel surface conditions: after the initiation of corrosion this ratio must 568 be quite high (e.g. 1:1) for the retardation of corrosion and if the steel is heavily corroded 569 complete repassivation is practically impossible,

570 - the efficiency of the inhibitor in solution with higher $\mathrm{pH}$ (simulated concrete pore solution 571 without chlorides) cannot be exactly assessed, because the inhibitor shows a buffering 572 effect,

573 - passivation due to the inhibitor is reached by the formation of an adsorbed layer on the

574 - steel surface,

575 - when the critical concentration ratio is not reached, the layer is partly destroyed, and the 576 corrosion damage is rather localized (localized corrosion spots can be relatively deep),

577 - when the stabilization of the passive state is reached due to the inhibitor and subsequently 578 the concentration of the inhibitor is reduced, the initiation of corrosion might reoccur (the 579 ratio of concentrations inhibitor/Cl- is critical also in such cases),

580 - the sooner the inhibitor is introduced after corrosion propagation the more effective it is,

581 - it can be expected that the long-term concentration of the inhibitor near the reinforcement, 582 which may decrease over time due to leaching and evaporation, is a crucial parameter for 583 the effectiveness of the inhibitor as part of a repair strategy 
- $\mathrm{Na}_{2} \mathrm{PO}_{3} \mathrm{~F}$ hydrolyses into the pore solution simulating the concrete to form phosphate and

585 so anodic formation of passive layer contributes to the decrease of chloride

586 aggressiveness.

587 - The corrosion currents measured for solution extract of blended cement were 588 significantly higher than those obtained at the same chloride concentration in the 589 mortar and pore solution.It was found that the corrosion currents of carbon steel 590 embedded in mortar immersion in $\mathrm{NaCl}$ at $3,5 \%$, would decrease due to the decrease 591 in the degree of pore saturation PS after 28 days. Regardless in the presence of 592 chloride content, the corrosion current was as low as $1,5 \mu \mathrm{A} / \mathrm{cm}^{2}$

\section{References}

[1] C. Monticelli, A.Frignani, G.Trabanelli, (2000), "A study on corrosion inhibitors

[2] B.Elsener, M.Büchler, Stalder, F., Böhni, H., (1999), "Migrating corrosion inhibitor blend for reinforced concrete: Part 1 - Prevention of corrosion", Corrosion, Vol. 55, No. 12, pp. 1155-1163.

[3] Mammoliti L, Hansson CM, Hope BB. Corrosion inhibitors in concrete. Part II: effect on chloride threshold values for corrosion of steel in synthetic pore solutions. Cem Concr Res 1999;29:1583-9.

[6] M Kawamura, S Tanikawa, RN Swamy, H Koto - Pore solution composition and

[4] Ngala VT, Page CL, Page MM. Corrosion inhibitor systems for remedial treatment of reinforced concrete. Part 1: Calcium nitrite.Corr Sci 2002;44:2073-87.

[5] Li Z.J., Ma B.G. Peng J. and Qi M., "The microstructure and sulfate resistance mechanism of high-performance concrete containing CNI", Cement \& Concrete Composites, 2000, 22, pp. 369-377. electrochemical behavior of steel bars in mortars with nitrite. ACI Special Publication, 1997.

[7] L Benzina Mechmeche, L Dhouibi, M. Ben Ouezdou, E. Triki, F. Zucchi.Investigation of the early effectiveness of an amino-alcohol based corrosion inhibitor using simulated pore solutions and mortar specimens. Cement and Concrete Composites, Volume 30, Issue 3, March 2008, Pages 167-173. 
[8] Heiyantuduwa R, Beushausen HD, Alexander MG. The effectiveness of corrosion inhibitors in concretes subjected to chloride attack and carbonation. BFT 2003:8.

[9] L.Li, A.A.Sagues, , N.Poor, "In situ leaching investigation of $\mathrm{pH}$ and nitrite concentration in concrete pore solution", Cement and Concrete Research, Vol. 29 (1999), pp. 315-321.

[10] L.Mammoliti, C.M., Hansson, B.B. Hope, "Corrosion inhibitors in concrete, Part II: Effect on chloride threshold values for corrosion of steel in synthetic pore solutions", Cement and Concrete Research, Vol. 29, (1999), pp. 1583-1589.

[11] J.Olek, , F.Martin, "Influence of corrosion inhibitors on the electrochemistry of corrosion processes of reinforcing steel in simulated pore solutions", Proceedings, Conference on Materials Problems in Civil Engineering, Cracow, (1996), pp. 302309.

[12] N.R. Short, , P.Lambert, , C.L. Page, ,"Effect of corrosion inhibitors on pore solution chemistry of hardened cement pastes", Proceedings, Second International Seminar on Durability of Concrete: Aspects of Admixtures and Industrial By-Products (editors: Berntsson, L.,Chandra, S., Nilsson, L.), Swedish Council for Building Research, Document D9-1989, (1989) pp. 218-228.

[13] Alonso C, Andrade C, Argiz C, Malric B. $\mathrm{Na}_{2} \mathrm{PO}_{3} \mathrm{~F}$ as inhibitor ofcorroding reinforcement in carbonated concrete. Cem Concr Res 1996;26(3):405-15.

[14] Hope BB, Thompson SV. Damage to concrete induced by calcium nitrite. ACI Mater J 1995;92(5):529-31.

[15] Lafave JM, Pfeifer DW, Sund DL, Lovett D, Civjan SA. Using mineral and chemical durability-enhancing admixtures in structural concrete. Concr Int 2002(August):71-8.

[16] Palmer R, Malric B. Surface applied inhibitors: conditions for application and control of penetration. In: International congress on advanced materials, their processes and applications. Munich, Ger-many; 2000.

[17] Nedal Mohamed. "Comparative Study of the Corrosion Behaviour of Conventional Carbon Steel and Corrosion Resistant Reinforcing Bars. A Thesis Submitted for the Degree of Master of Science University of Saskatchewan. August 2009.

[18] Pruckner, F. (2001). ""Corro sion and Protection of Re inforcement in Concrete Measurements and Interpretation"." $\mathrm{PhD}$ thesis, University of Vienna.

[19] Sahoo, G., and Balasubramaniam, R. (2008). "On the corrosion behaviour of phosphoric irons in emulated concrete pore solu tion." Corrosion Science, 50(1), 131.

[20] ASTM Standard C876-99. "Standard Test Method for Half-Cell Potentials of Uncoated Reinforcing Steel in Concrete." ASTM International, West Conshohocken, PA, 1999, DOI: 10.1520/C0876-91R99, Www.Astm.Org. (1999). 
[21] Andrade C., Alonso A \& Al., "Test method for on-site corrosion rate measurement of steel reinforcement in concrete by means of the polarization resistance method", RILEM TC 154-EMC: Electrochemical Techniques for Measuring Metallic Corrosion - Recommendations, Materials and Structures, Vol. 37, n 9 , 2004, pp.623643.

[22] Simescu F.., Idrissi H., "Corrosion behaviour in alkaline medium of zinc phosphate coated steel obtained by cathodic electrochemical treatment", Corrosion Science. vol.

[23] Smialowska Szlarska-H. Oranowska, Z. An electrochemical and ellipsometric investigation of surface films grown on iron in saturated calcium hydroxide solutions with or without chloride ions. Corrosion Science 21 (1981) 735.

[24] Smialowska. T Zakroczymski, Z Szklarska .Activation of the iron surface to hydrogen absorption resulting from a long cathodic treatment in $\mathrm{NaOH}$ solution Journal of the Electrochemical Society1985.

[25] Jamil HE, Montemor MF, Boulif R, Shriri A, Ferreire MGS. An electrochemical and analytical approach to the inhibition mechanism of an amino-alcohol-based corrosion inhibitor for reinforced concrete. Electrochim Acta 2003; 48:3509-18.

[26] So“ ylev T.A, M.G. Richardson. Corrosion inhibitors for steel in concrete: State-of-

[27] Hausmann, D. A. (1967). "Steel corrosion in concrete - How does it occur." Materials Protection, 6(11), 19.

[28] Li, L., and Sagues, A. A. "Chloride corrosion threshold of reinforcing steel in alkaline solutions - Open-circuit immersion tests." Corrosion, 57(1), 19. (2001).

[29] El-Jazairi B., and Berke N.S., "the use of calcium nitrites as corrosion inhibiting admixture to steel reinforcement in concrete". Elsevier Science Publishers Ltd ., Wishaw, Warwickshire, UK. 1992.

[30] Berke, N.S., Weil, T.G., (1994), "World wide review of corrosion inhibitors in concrete" Ad-vances in Concrete Technology (editor: Malhotra, V.M.), CANMET, Montreal, pp. 891-914.

[31] Trejo, D., and Pillai, R. (2004). "Accelerated chloride threshold testing - Part II: Corrosion-resistant reinforcement." AC I Materials Journal, 101(1), 57

[32] Qian, S., Cusson, D., Chagnon, N., and Ba ldock, B. (2008). "Corrosion-Inhibiting systems for durable concrete bridges. II: A ccelerated laboratory investigation." Journal of Materials in Civil Engineering, 20(1), 29. and Ezzeddine Triki. Electrochemical study of corrosion inhibition of steel 
reinforcement in alkaline solutions containing phosphates based components Naceur Etteyeb, Journal of Materials Science Volume 42, Number 13 (2007), 4721 4730, DOI: $10.1007 /$ s10853-006-0880-3

692

693

[34] Jamil HE, Shriri A, Boulif R, Montemor MF, Ferreire MGS.Corrosion behaviour of 694 reinforcing steel exposed to an amino alcoholbased corrosion inhibitor. Cem Concr Com 2005;27(6):671-8. 